\title{
Desempenho de Bovinos Confinados Alimentados com Dietas à Base de Farelo de Algodão, Uréia ou Amiréia
}

\author{
José Renato Caleiro Seixas ${ }^{2}$, Jane Maria Bertocco Ezequiel ${ }^{3}$, Walter de Albuquerque Araújo ${ }^{4}$, \\ Flavio Dutra de Resende ${ }^{5}$, Ademir Martins Junior ${ }^{*}$, Sérgio do Nascimento Kronka ${ }^{3}$, Leandro \\ das Dores Ferreira da Silva ${ }^{7}$, Juliana Borsari Dourado ${ }^{*}$, Weber Vilas Boas Soares ${ }^{6,{ }^{* *}}$
}

\begin{abstract}
RESUMO - O objetivo deste experimento foi avaliar o desempenho de bovinos em confinamento alimentados com rações suplementadas com concentrados protéicos à base de farelo de algodão (AL), uréia (UR) ou amiréia (AM), tendo como volumoso silagem de milho. O confinamento teve duração de 80 dias. As rações foram compostas mantendo a proporção volumoso:concentrado no nível de 63:37, com aproximadamente 13\% PB. Não se constataram diferenças quanto ao ganho de peso diário (GDP) durante o período experimental total entre os tratamentos AL, UR ou AM (1,14; 1,17; e 1,23 kg/anim. •dia), ou na ingestão de MS em \% PV (2,63; 2,60; e 2,60\% PV), em g/kg0,75•dia $(136,19 ; 134,74$; e 134,81) ou kg/anim. •dia $(9,42 ; 9,35$; e 9,40), respectivamente. Os valores de ingestão de PB foram de 1,28; 1,24; e 1,34 kg de PB/anim. •dia e de 18,54; 17,86; e 19,24 g/kg0,75 •dia para os tratamentos AL, UR ou AM, não diferindo entre si. Valores obtidos para conversão alimentar da matéria seca foram de 8,41; 8,01; e 7,67 kg MSI/kg GPD e para conversão protéica, 1,15; 1,06; e 1,09 kg PBI/kg GPD, respectivamente, para os tratamentos AL, UR e AM, que foram semelhantes.
\end{abstract}

Palavras-chave: amiréia, confinamento, farelo de algodão, ruminantes, uréia

\section{Performance of Beef Cattle in Feedlot Feeding with Diets Based on Cottonseed Meal, Urea or Starea}

\begin{abstract}
The objective of this experiment was to evaluate the performance of feedlot beef cattle fed diets supplemented with protein concentrate based on cottonseed meal (CSM) urea (UR) or starea (ST), using corn silage as forage. The feedlot period was 80 days. The diets were constituted maintaining the forage:concentrate proportion in the $63: 37$ level, with nearly $13 \% \mathrm{CP}$. No difference was observed in daily weight gain during the experimental period among the CSM, UR or ST treatments $(1.14,1.17$, and $1.23 \mathrm{Kg}$ /anim $\bullet$ day) or in the dry matter intakes in \% LW $\left(2.63,2.60\right.$, and 2.60), g/ $\mathrm{kg}^{0.75} \cdot$ day $(136.19,134.74$, and 134.81) or kg/anim. $\cdot$ day $(9.42,9.35$, and 9.40), respectively. The CP intakes values were $1.28,1.24$, and $1.34 \mathrm{~kg}$ of CP/anim. day and $18.54,17.86$, and $19.24 \mathrm{~g} / \mathrm{kg} \cdot{ }^{75} \cdot$ day for the CMS, UR or ST treatments and they did not differ among each other. Values of feed:gain ratios obtained for dry matter were 8.41,8.01, and 7.67 kg DMI/kg DWG and for the protein:gain ratios, 1.15, 1.06, and 1.09 kg CPI / Kg DWG, respectively, for the CPM, UR and ST treatments, that were similar.
\end{abstract}

Key Words: starea, feedlot, cottonseed meal, ruminant, urea

\section{Introdução}

As rações fornecidas durante o confinamento são oriundas da combinação de diferentes alimentos, mas o custo dos concentrados dificulta a prática; portanto, esse fato implica na procura de ingredientes que proporcionem combinação adequada com maior economia.

Os farelos protéicos naturais, como os de algodão, soja, amendoim e girassol, são eficientes na suplementação protéica, mas possuem a desvanta- gem de ter custo mais elevado por unidade de nitrogênio que as fontes de nitrogênio não-protéico (NNP), como a uréia (SWINGLE et al., 1977).

A eficiência da utilização de nitrogênio ou amônia pelos microrganismos do rúmen é maior quando a uréia é utilizada em dietas com baixo nível de nitrogênio e elevados níveis de energia, minerais e outros componentes que aumentam a atividade microbiana (CAMPOS e RODRIGUES, 1985). Das fontes de energia disponíveis, o amido é a mais

\footnotetext{
${ }^{1}$ Parte da Dissertação apresentada à Faculdade de Ciências Agrárias e Veterinárias, UNESP, Jaboticabal, pelo primeiro autor, como requisito para obtenção de título de Mestre em Zootecnia, Área de Concentração em Produção Animal

2 Zootecnista, Gerente Técnico da RAÇÕES FRI-RIBE S.A. - 14.750 .000 - Pitangueiras, SP.

3 Professor da FCAVJ - UNESP - Jaboticabal SP - 14.870.000

4 Médico Veterinário, Diretor Técnico da RAÇÕES FRI-RIBE S.A. - 14.750 .000 - Pitangueiras, SP.

5 Zootecnista, M.S., Estação Experimental de Zootecnia - 14.770 .000 - Colina, SP.

6 Zootecnista formado pela FCAVJ-UNESP - 14.870.000 - Jaboticabal, SP.

$7^{*}$ Bolsista FAPESP. ${ }^{* *}$ Bolsista CNPq.
} 
satisfatória, por ser fermentada à taxa relativamente constante (MAYNARD et al., 1979).

Apesar dos estudos já existentes com a utilização das fontes protéicas citadas, o aprimoramento de tecnologia nas confecções de concentrados protéicos que aliem desempenho e custos positivos é quase inexistente. Um exemplo seria as fontes de nitrogênio não-protéico, como a uréia. O uso da uréia pelos ruminantes é limitado em virtude de sua baixa aceitabilidade, sua segregação, quando misturada com farelos, e sua toxicidade (CHALUPA, 1968), agravada pela sua elevada solubilidade no rúmen, o que a transforma muito rapidamente em amônia (OWENS et al., 1980; DAUGHERTY e CHURCH, 1982), devido à ação da enzima urease produzida pelos microrganismos ruminais (OWENS e ZINN, 1988; REYNOLDS, 1992).

Qualquer metodologia que efetivamente torne a uréia solúvel à taxa mais lenta do que quando fornecida in natura poderia conduzir à sua otimização em dietas para ruminantes, desde que adequadamente balanceadas para esse fim. A liberação gradual de $\mathrm{NH}_{4}$ permite aos microrganismos do rúmen síntese contínua de proteína celular (CASS et al., 1994; PARRÉ, 1995).

Há, entre os pesquisadores, a preocupação de se estudarem maneiras que permitam a hidrólise mais lenta da uréia no rúmen e, conseqüentemente, a menor concentração de amônia, logo após o consumo de alimento com uréia (OWENS e BERGEN, 1983). Processos físicos, como o de extrusão, diminuem a sua degradação, tornando-a compatível ao nível de energia disponível, o que é atribuído ao processo que une a uréia à molécula de amido gelatinizado, diminuindo a solubilidade daquela, tornando seu emprego mais seguro.

O produto resultante da extrusão do amido com a uréia, conhecido como amiréia, pode acarretar efeitos positivos na utilização da uréia para ruminantes. Este fato foi evidenciado por HELMER (1970), que, em experimento in vitro, notou concentrações $(\mathrm{mg} /$ $100 \mathrm{~mL}$ ) maiores de proteína microbiana e menores de amônia no fluido ruminal, o que pode ser conseqüência do aumento na eficiência dos microrganismos em usar a amiréia como substrato na produção de proteínas. Foi constatado também que a proteína microbiana produzida possui mais aminoácidos essenciais. SILVA et al. (1994), utilizando palha de arroz desintegrada como volumoso e concentrados e amiréia (48,9\% de PB na MS), fubá de milho+uréia (50\% de PB na MS) e farelo de soja, em ensaio de digestibilidade com ovinos, obtiveram, respectivamente, os coeficientes de digestibilidade médios de 52,0;
56,8 ; e 58,0 para a matéria seca e 78,$5 ; 81,7$; e 78,8 para a proteína bruta. Os teores de NDT obtidos neste experimento foram de 74,$05 ; 67,27$; e $62,5 \%$ para a amiréia, fubá+uréia e farelo de soja, respectivamente.

O objetivo deste trabalho foi avaliar o desempenho de bovinos alimentados com três diferentes fontes protéicas, amiréia 30 , uréia ou farelo de algodão, em regime de confinamento.

\section{Material e Métodos}

Foi realizado confinamento de engorda com bovinos, para a avaliação do desempenho. Utilizou-se a silagem de milho como único volumoso e os ingredientes dos concentrados foram: grão de milho moído (peneira de $3 \mathrm{~mm}$ ), farelo de algodão, uréia (45\% de nitrogênio) e amiréia 30. A mistura mineral oferecida à vontade nos cochos aproriados foi composta pelos seguintes níveis por kg: Fósforo 80 g, Cálcio 200 g, Sódio 123 g, Zinco $2000 \mathrm{mg}$, Manganês $1000 \mathrm{mg}$, Cobre $400 \mathrm{mg}$, Iodo $50 \mathrm{mg}$, Cobalto $50 \mathrm{mg}$ e Selênio $5 \mathrm{mg}$.

A amiréia 30 é o resultado do processamento de fonte de amido com uréia, por meio do processo de extrusão, perfazendo, neste caso, produto com 30\% de proteína bruta $(\mathrm{N} \times 6,25)$. A composição química dos alimentos utilizados encontra-se na Tabela 1.

O experimento foi realizado na Estação Experimental de Zootecnia de Colina do Instituto de Zootecnia de São Paulo. Os animais foram confinados em instalação de alvenaria e cobertas, com 15 subdivisões para dois animais em cada, munidas de bebedouros e cochos para a mistura mineral. Foram utilizados 30 bovinos cruzados (Bos taurus taurus $\mathrm{x}$ Bos taurus indicus), castrados, com idade aproximada de 18 meses e peso médio de $300 \mathrm{~kg}$. Os animais foram distribuídos ao acaso nos tratamentos, em número de 10 animais por tratamento; posteriormente, foram divididos aleatoriamente em dois animais por subdivisão e encaminhados às instalações para o período pré-experimental, no qual foram realizadas adaptações dos animais ao local, manejo e alimentos utilizados.

O volumoso utilizado foi a silagem de milho, produzida no Setor de Bovinos de Leite da Estação Experimental de Zootecnia de Colina SP e retirada de silos tipo trincheira e de superfície, diariamente, nos horários da alimentação.

Os tratamentos testados neste ensaio receberam as denominações referentes aos tipos de concentrados utilizados, sendo: $\mathrm{AM}=$ Silagem de milho + Concentrado Amiréia; $\mathrm{AL}=$ Silagem de milho + Concentrado Farelo de Algodão; e UR = Silagem de 
434 Rev. bras. zootec.

Tabela 1 - Composição quimica do ingrediente na ração

Table 1 - Chemical composition of the ingredient of the diet

\begin{tabular}{lccc}
\hline $\begin{array}{l}\text { Ingrediente } \\
\text { Ingredient }\end{array}$ & $\begin{array}{c}\text { Matéria seca (\%) } \\
\text { Dry matter }\end{array}$ & $\begin{array}{c}\text { Proteína bruta }(\% \mathrm{MS}) \\
\text { Crude protein }(\% \text { DM) }\end{array}$ & $\begin{array}{c}\text { Energia metabolizável calculada (Mcal/kg MS) } \\
\text { Calculated betabolizable energy (Mcal/kg DM) }\end{array}$ \\
\hline $\begin{array}{l}\text { Milho } \\
\text { Corn }\end{array}$ & 89,8 & 10,0 & $3,18^{1}$ \\
$\begin{array}{l}\text { Farelo de algodão } \\
\text { Cottonseed meal }\end{array}$ & 90,1 & 35,1 & $2,71^{1}$ \\
$\begin{array}{l}\text { Amiréia } \\
\text { Starea }\end{array}$ & 93,5 & 38,8 & $1,97^{2}$ \\
Uréia & - & 281,2 & - \\
$\begin{array}{l}\text { Urea } \\
\text { Silagem de milho } \\
\text { Corn silage }\end{array}$ & 32,6 & 8,8 & $2,39^{1}$ \\
$\begin{array}{l}\text { 1 NRC (1996). } \\
\text { 2 Campos (1978). }\end{array}$ & & & \\
\end{tabular}

milho+Concentrado Uréia.

A proporção dos ingredientes nos concentrados é apresentada na Tabela 2 e sua proporção na ração mista total, na Tabela 3 .

Foram fornecidas duas refeições diárias aos animais. Na primeira, pela manhã, foi oferecida metade do alimento total. Na segunda refeição, no período da tarde, foi distribuído o restante do alimento. As sobras de alimento foram obtidas diariamente e amostradas (5\% do total) antes da primeira refeição. O fornecimento de alimentos ocorreu de forma a se obterem $20 \%$ de sobras diariamente. Este procedimento foi realizado no sentido da avaliar o real consumo diário, além de propiciar o aumento no consumo dos alimentos. O confinamento teve a duração de 80 dias, após um período pré-experimental de 21 dias, durante o qual os animais foram adaptados às condições experimentais. A amiréia e o sal mineralizado foram produzidos e doados pelas Rações Fri-Ribe S.A. Durante o período de adaptação e o período experimental foram realizadas amostragens semanais do volumoso e dos concentrados destinadas à análise bromatológica dos alimentos utilizados.

Os animais foram pesados individualmente ao início, aos 21, 42, 63 e 80 dias de confinamento. A proporção volumoso: concentrado foi mantida durante todo o experimento.

Para determinação da matéria seca parcial dos alimentos e sobras, utilizou-se estufa com circulação forçada de ar com temperatura regulada entre $55 \mathrm{e}$ $60^{\circ} \mathrm{C}$ por 72 horas. Após pré-secagem, as amostras foram moídas em moinho tipo Willey com peneira de $1 \mathrm{~mm}$. Para a moagem do concentrado foi utilizado moinho tipo bola.

As análises químico-bromatológicas das amostras de alimento (concentrado e volumoso) e sobras foram feitas logo após a moagem das mesmas. A
Tabela 2 - Proporção do ingrediente nos concentrado (\% MS)

Table 2 - Ingredient proportion in the concentrate (\% DM)

\begin{tabular}{lccc}
\hline $\begin{array}{l}\text { Ingrediente } \\
\text { Ingredient }\end{array}$ & \multicolumn{3}{c}{$\begin{array}{c}\text { Concentrado } \\
\text { Concentrate }\end{array}$} \\
\cline { 2 - 4 } & $\mathrm{AL}$ & $\mathrm{UR}$ & $\mathrm{AM}$ \\
\hline $\begin{array}{l}\text { Amiréia } \\
\text { Starea }\end{array}$ & - & - & 41,52 \\
$\begin{array}{l}\text { Farelo algodão } \\
\text { Cottonseedmeal }\end{array}$ & 41,52 & - & - \\
$\begin{array}{l}\text { Uréia } \\
\text { Urea }\end{array}$ & - & 3,48 & - \\
$\begin{array}{l}\text { Milho moído } \\
\text { Ground corn }\end{array}$ & 58,48 & 96,52 & 58,48
\end{tabular}

Tabela 3 - Proporção dos ingredientes na ração total (\% MS) e relação volumoso:concentrado

Table 3 - Ingredients proportion in the total mixed diet (\% DM) and the forage:concentrate ratio

\begin{tabular}{|c|c|c|c|}
\hline \multirow[t]{3}{*}{$\begin{array}{l}\text { Ingrediente } \\
\text { Ingredient }\end{array}$} & \multicolumn{3}{|c|}{$\begin{array}{l}\text { Ração total } \\
\text { Total diet }\end{array}$} \\
\hline & $\mathrm{AL}$ & UR & $\mathrm{AM}$ \\
\hline & CSM & $U R$ & $S T$ \\
\hline Silagem de milho & 63,0 & 63,0 & 63,0 \\
\hline Corn silage & & & \\
\hline Milho & 21,6 & 35,7 & 21,6 \\
\hline Corn & & & \\
\hline Farelo algodão & 15,4 & - & - \\
\hline Cottonseed meal & & & \\
\hline Uréia & - & 1,3 & - \\
\hline Urea & & & \\
\hline Amiréia & - & - & 15,4 \\
\hline Starea & & & \\
\hline$\% \mathrm{~PB}(\% C P)$ & 13,4 & 13,0 & 13,9 \\
\hline $\begin{array}{l}\text { Energiametabolizável } \\
(\mathrm{kcal} / \mathrm{kg} \mathrm{MS})^{1}\end{array}$ & 2436,02 & 2379,73 & 2556,75 \\
\hline $\begin{array}{l}\text { Metabolizable energy } \\
\text { (kcal/lg DM) }\end{array}$ & & & \\
\hline Custo da ração (R $\$ / \mathrm{kg}$ MS) & 0,0864 & 0,0831 & 0,0871 \\
\hline Cost of the diet (R\$/kg DM) & & & \\
\hline Relação Vo:Co(\%) & $63: 37$ & $63: 37$ & $63: 37$ \\
\hline Forage:concentrate ratio (\%) & & & \\
\hline
\end{tabular}


determinação de matéria seca (MS) e N total foi feita segundo SILVA (1981).

Os resultados foram analisados com base na análise de variância, considerando-se o peso inicial como variável auxiliar. O delineamento experimental utilizado foi em bloco casualizado com três tratamentos e 10 blocos, segundo o modelo matemático:

em que

$$
\mathrm{Y}_{\mathrm{ij}}=\mathrm{m}+\mathrm{t}_{\mathrm{i}}+\mathrm{b}_{\mathrm{j}}+\alpha \mathrm{X}_{\mathrm{ij}}+\mathrm{e}_{\mathrm{ij}}
$$

$\mathrm{Y}_{\mathrm{ij}}=$ valor da variável dependente no tratamento i no bloco j;

$\mathrm{m}=$ média geral;

$\mathrm{t}_{\mathrm{i}}=$ efeito do tratamento $\mathrm{i}$;

$\mathrm{b}_{\mathrm{j}}=$ efeito do bloco $\mathrm{j}$;

$\alpha=$ coeficiente de regressão linear;

$\mathrm{X}_{\mathrm{ji}}=$ valor da variável auxiliar no tratamento i no bloco j; e

$\mathrm{e}_{\mathrm{ij}}=$ efeito do acaso na parcela com tratamento $\mathrm{i}$ no bloco j.

Como teste de médias foi utilizado o teste de Tukey a 5\% (STEEL e TORRIE, 1960).

\section{Resultados e Discussão}

$\mathrm{Na}$ Tabela 4 encontram-se os resultados de ingestão de matéria seca (IMS) em \% de peso vivo, $\mathrm{g} / \mathrm{UTM} /$ dia e $\mathrm{kg} /$ cabeça/dia para os três tratamentos estudados. Constata-se que não houve diferenças para as médias de ingestão de matéria seca em todas as variáveis para os três tratamentos. Na Tabela 4 também são demonstrados os resultados de ingestão de proteína bruta (IPB) em g/UTM/dia e kg/cabeça/ dia para as três fontes protéicas. Entre os tratamentos não houve diferenças para as médias de ingestão de proteína. O fato de as quantidades de matéria seca ingeridas pelos animais nos diferentes tratamentos apresentarem igualdades estatísticas pode ser relacionada ao teor de proteína das rações experimentais, $13,3 \%$ para a $A L, 13 \%$ para a UR e $13,9 \%$ para a AM. Os valores numéricos das médias obtidas também foram bastante próximos, demonstrando a igualdade entre os tratamentos. Este fato demonstrou que a amiréia não apresentou qualquer problema em relação a sua palatabilidade para os bovinos. De acordo com STILES et al.(1970), a extrusão provoca a incorporação da uréia na estrutura do amido, o que promove melhora na aceitabilidade do concentrado.

Segundo ØRSKOV (1982), conhecer a natureza protéica da dieta é importante para maximizar o desempenho dos ruminantes. Assim, é necessário estabelecer a concentração limite de amônia ruminal.
Tabela 4 - Ingestão de matéria seca e proteína bruta obtida durante o período de confinamento para os diferentes tratamentos

Table 4 - Dry matter and crude protein intakes during the feedlot period for the different treatments

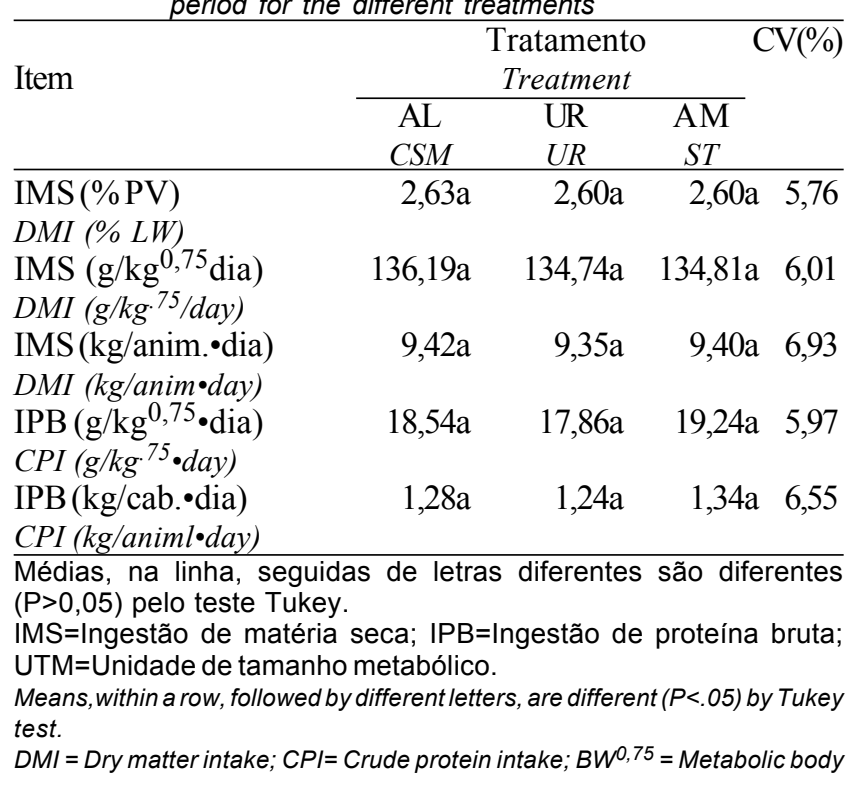

Quando a amônia se torna limitante, ocorre diminuição da produção dos microrganismos no rúmen (RUSSEL, 1992) e tanto a taxa de digestão como a taxa de passagem do alimento no rumem diminuem. Conseqüentemente, o esvaziamento no rúmen tornase lento, afetando o consumo do alimento (OWENS e ZINN, 1988; SAMPAIO, 1989). OWENS e ZINN (1988) e RUSSEL et al. (1992) observaram que o nitrogênio não protéico é utilizado com grande eficiência pelos microrganismos celulolíticos. Dessa forma, a relação de volumoso:concentrado desta pesquisa $(63: 37)$ pode ter causado maior crescimento dos microorganismos celulolíticos, o que, conseqüentemente, resultou em maior eficiência do uso do NNP. Este fato foi demonstrado pela melhor digestibilidade do FDN na ração AM em experimento anterior a este (SALMAN et al., 1997), utilizando as mesmas rações no arraçoamento de ovinos. Portanto, a extrusão pode causar diminuição na solubilidade do NNP, acarretando melhor sincronismo ruminal, otimizando a ação deste sobre a digesta.

A fonte de nitrogênio que é utilizada pelos microrganismos do rúmen para a síntese de proteína é composta tanto da proteína dietética, como do nitrogênio reciclado no rúmen. Em muitas situações alimentares, o nitrogênio que atinge o intestino é, em grande parte, de origem microbiana; portanto, o crescimento microbiano tem grande influência na utiliza- 
436 Rev. bras. zootec.

ção da proteína pelos ruminantes. O NRC (1996) concluiu que todas as dietas apresentaram deficiência em proteína metabolizável, mas não em proteína degradável no rúmen. Portanto, ao avaliar a IPB nos tratamentos AL, UR e AM $(1,28 ; 1,24 ;$ e $1,34 \mathrm{~kg} / \mathrm{cab} /$ dia), pode-se concluir que as ingestões numéricas maiores de $\mathrm{PB}$ para as rações AM podem ser causadas pela melhor aceitabilidade da dieta.

Os valores obtidos para ganho de peso diário (GPD), conversão alimentar (CA) e conversão protéica (CP) são demonstrados na Tabela 5. Para as médias obtidas de ganho em peso entre os tratamentos, não foram observadas diferenças.

O ganho de peso diário médios para os tratamentos AL e UR foi de 1,14 e 1,17 kg/cabeça, respectivamente, sendo estes superiores aos obtidos por COUTINHO FILHO (1993), de 786 e 613 g/cabeça, para tratamentos contendo farelo de algodão e uréia, respectivamente, como fontes de proteína em rações completas. Este menor ganho pode ser atribuído ao volumoso utilizado, pois se utilizou cana de açúcar, encontrando redução de $22,12 \%$ no ganho de peso, quando se utilizou a uréia comparada ao uso do farelo de algodão. Este efeito não foi observado neste trabalho.

De acordo com BOIN e MOURA (1977), o ganho de peso vivo observado é normalmente superior ao esperado pelas exigências calculadas para outros países; por conseguinte, é evidente que faltam dados básicos de requerimentos de proteína para os

Tabela 5 - Ganho de peso diário e conversão alimentar e protéica obtidos durante o período de confinamento para os diferentes tratamentos

Table 5 - Daily weigth gain, feed:gain ratio and:protein:gain ratio obtained during the feedloot period for the diferent treatments

\begin{tabular}{|c|c|c|c|c|}
\hline \multirow[t]{2}{*}{ Item } & \multicolumn{4}{|c|}{$\begin{array}{l}\text { Tratamento } \\
\text { Treatment }\end{array}$} \\
\hline & $\begin{array}{l}\mathrm{AL} \\
C S M\end{array}$ & $\begin{array}{l}\mathrm{UR} \\
U R\end{array}$ & $\begin{array}{c}\mathrm{AM} \\
S T\end{array}$ & \\
\hline$\overline{\mathrm{GPD}}(\mathrm{kg} / \mathrm{dia})$ & $1,14 \mathrm{a}$ & $1,17 \mathrm{a}$ & $1,23 a$ & 12,96 \\
\hline$D W G(\mathrm{~kg} /$ day $)$ & & & & \\
\hline $\begin{array}{l}\text { CA (kg MS ingerida/ kg GPD) } \\
F: G(k g D M \text { intake } / \mathrm{kg} D W G)\end{array}$ & $8,41 \mathrm{a}$ & $8,01 \mathrm{a}$ & $7,67 \mathrm{a}$ & 8,08 \\
\hline $\begin{array}{l}\mathrm{CP}(\mathrm{kg} P B \text { ingerida/kg GPD }) \\
P: G(\mathrm{~kg} C P \text { intake } / \mathrm{kg} D W G)\end{array}$ & $1,15 \mathrm{a}$ & $1,06 \mathrm{a}$ & $1,09 \mathrm{a}$ & 7,73 \\
\hline $\begin{array}{l}\text { Médias, na linha, seguidas de le } \\
\text { ( } P>0,05) \text { pelo teste Tukey. } \\
\text { GPD = Ganho de peso diário; CA } \\
\text { Conversão protéica. } \\
\text { Means, within a row, followed by different } \\
\text { test. } \\
\text { DWG= Daily weight gain; } F: G=F e e d: \text { gai }\end{array}$ & $\begin{array}{l}\text { tras di } \\
=\text { Con }\end{array}$ & $\begin{array}{l}\text { entes } \\
\text { são al al }\end{array}$ & ão dife & $\begin{array}{l}\text {; } \mathrm{CP}= \\
\text { y Tukeytes }\end{array}$ \\
\hline
\end{tabular}

zebuinos, em especial de proteína degradável, frente à ingestão de volumos tropicais, ricos em fibra.

Os valores $8 \%$ mais elevados obtidos para os ganhos em peso diários dos tratamentos AM em relação ao tratamento FA podem estar relacionados com as maiores ingestões de proteína degradável no rúmen nestes tratamentos, associadas ao volumoso utilizado, que contém considerável quantidade de carboidratos, influenciando o sincronismo do crescimento microbiano e as exigências de carboidratos e proteína disponíveis no rúmen. Segundo o NRC (1989), a degradabilidade da proteína bruta para a silagem de milho é de $69 \%$ e para o farelo de algodão, a uréia e o milho grão moído, respectivamente, de 57, 100 e $48 \%$, o que resultaria em ingestões de 0,$748 ; 0,860$; e $0,906 \mathrm{~kg}$ de proteína degradável no rúmen/cabeça/dia para as rações AL, UR e AM, respectivamente. De acordo com o NRC (1989), a exigência de bovinos com peso vivo médio de 313 e $407 \mathrm{~kg}$ é de 0,430 e $0,596 \mathrm{~kg}$ de proteína degradável/cab/dia. Não houve, assim, necessidade de maior quantidade de proteína degradável no rúmen, uma vez que foram suficientes para atender às exigências microbianas. A estimativa da proteína degradável para a amiréia foi feita assumindo que a extrusão diminui em $20 \%$ a degradabilidade da uréia pelo processo de gelatinização com o amido. De acordo com a estimativa NRC (1996), a quantidade de proteína degradável no rúmen é de $850 \mathrm{~g} / \mathrm{cab} / \mathrm{dia}$, para animais Nelore de 300 a $450 \mathrm{~kg}$ de peso. Da mesma forma, comparativamente as rações com farelo de algodão satisfazem sem excessos o requerimento em proteína degradável e as com NNP apresentaram pequeno excesso. Para todas as rações houve atendimento de $380 \%$ de FDNe, considerando-se que a silagem contenha $25 \%$ de grãos (NRC, 1996).

Os resultados obtidos no presente ensaio são diferentes dos de exigência nutricional apresentados por BOIN (1992) para bovinos com peso vivo de 300 $\mathrm{kg}$ (bovinos machos castrados em crescimento e acabamento), que apresentaram exigências diárias para se obterem ganhos em peso médios de 1,0 e 1,2 $\mathrm{kg} / \mathrm{cab}$./dia, respectivamente, de 7,54 e 7,61 kg de MS e 0,890 e $0,951 \mathrm{~kg}$ de $\mathrm{PB}$; neste trabalho, usando animais de peso médio inicial de $312,5 \mathrm{~kg}$, foi obtida ingestão de MS da ordem de 8,16 e 1,094 kg de PB, apresentando ganhos de peso acima de $1,1 \mathrm{~kg}$. Isto indica que a quantidade maior de proteína ingerida pelos animais deve ter sido aproveitada como energia, ou o maior consumo de proteina degradavél no rúmen ocasionou incremento no ganho em peso, além 
de estimular maior consumo de matéria seca.

Deve-se observar o comportamento da variável ganho em peso nos períodos entre as pesagens (Figura 1). As rações contendo amiréia apresentaram declínio suave e clássico no ganho em peso, mas levaram a elevados valores de ganho nos dois primeiros subperíodos estudados. Isto significa que o uso de amiréia, seja pela forma presente do amido, ou pela forma de liberação de amônia no rúmen, proporcionaria maior aproveitamento energético das rações. As rações com uréia continham $65 \%$ mais de milho que as com amiréia, mas conduziram a ganhos em peso iniciais comparativamente mais baixos.

A melhor média numérica da conversão alimentar obtida para a ração $\mathrm{AM}(7,67 \mathrm{Kg} \mathrm{MS} / \mathrm{kg}$ GPD), comparada às rações AL e UR (respectivamente, 8,41 e $8,01 \mathrm{~kg}$ MS/Kg GPD), pode ser atribuída à melhora da digestibilidade na MS pelo processo da extrusão (SALMAN et al., 1997).

Os índices de conversão alimentar encontrados na literatura são distintos em razão de diversas variáveis nos experimentos, como idade dos animais, período experimental, raça, sexo e rações testadas; os resultados obtidos neste ensaio indicam bons valores para o tratamento com uréia. COUTINHO FILHO (1993), em trabalho com bovinos em confinamento, utilizando como fontes protéicas o farelo de algodão com línter ou uréia e como volumoso a cana de açúcar, obteve valores de conversão alimentar de 10,3 e 11,3 kg MS/kg GPD, respectivamente, para o farelo de algodão e a uréia.

Apesar de não apresentarem diferenças estatísticas para os valores de conversão protéica, consumo de proteína bruta para a obtenção de $1 \mathrm{~kg}$ de GPD,

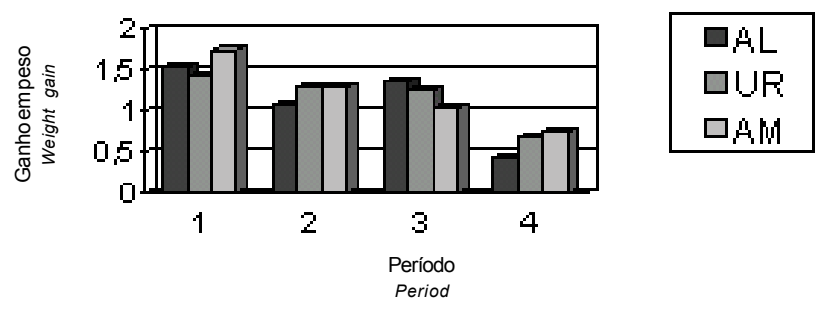

Figura 1- Ganhos de peso dos bovinos nos períodos entre as pesagens.

Figure 1 - Weight gains of bovines in the different weighing period. os resultados foram ligeiramente positivos para as rações UR e AM (1,06 e 1,09 kg, respectivamente) em relação à ração $\mathrm{AL}(1,15 \mathrm{~kg})$. Isto pode ter ocorrido em virtude do bom sincronismo dos carboidratos disponíveis e a produção de amônia no rúmen para as fontes de NNP (tratamentos UR e AM), que otimizaram a produção de proteína microbiana, a qual foi utilizada pelos bovinos. Estes resultados assemelham-se aos obtidos por COUTINHO FILHO (1993), que obteve valores para a CP de $0,94 \mathrm{~kg}$ para a ração com o farelo de algodão e $1,09 \mathrm{~kg}$ para a ração com uréia, ambas associadas ao milho moído como fonte energética.

\section{Conclusões}

Mesmo não obtendo diferenças no ganho em peso vivo diário, conversão alimentar, ingestão de matéria seca, ingestão de proteína bruta e conversão protéica, no período total de confinamento com bovinos, o uso da amiréia em confinamento de bovinos pode ser alternativa para a melhoria no desempenho animal, em especial nos primeiros 40 dias de confinamento.

Novos estudos devem ser realizados utilizando a amiréia em rações de ruminantes com a utilização de outras fontes energéticas e principalmente de volumosos, assim como a avaliação da amiréia quanto ao $\mathrm{N}$-reciclado e à taxa de absorção de $\mathrm{N}^{-\mathrm{NH}_{3}}$ no rúmen e na produção de microrganismos no rúmen.

\section{Referências Bibliográficas}

BOIN, C. Nutrição e manejo da alimentação de bovinos de corte em confinamento. In: SIMPÓSIO DO COLÉGIO BRASILEIRO DE NUTRIÇÃO ANIMAL, 4, SEMINARIO SOBRE TECNOLOGIA DE PRODUÇÃO DE RAÇÕES, 3, Campinas. Anais... Campinas, p. 27-61, 1992.

BOIN, C., MOURA, M.P. 1977. Comparação entre dois níveis de proteína bruta e entre dois níveis de energia para zebuínos em crescimento. Bol. Ind. Anim., 34(2):155-63.

CAMPOS, J. 1980. Tabelas para cálculos de rações: Viçosa, Imprensa Universitária, $46 \mathrm{p}$.

CAMPOS, O.F., RODRIGUES, A.A. 1985. Uréia para bovinos em crescimento. EMBRAPA/CNPGL, 42p.

CASS, J.L., RICHARDSON, C.R., SMITH, K.J. 1994. Evaluation of slow ammonia release from urea/calcium compounds. J. Anim. Sci.,72:234, (suppl. 1).

CHALUPA, W. 1968. Problems in feed urea to ruminants. $J$. Anim. Sci., 27:207.

COUTINHO FILHO, J.L.V. Estudo de rações compostas por diferentes fontes denitrogênio através do desempenho e digestibilidade aparente com ruminantes. Jaboticabal, 1993. 69p. Dissertação (Mestrado em Zootecnia) - Faculdade de Ciências Agrárias e Veterinárias, Universidade Estadual Paulista, 1993.

DAUGHERTY, D.A., CHURCH, D.C. 1982. In vivo and in vitro 
438 Rev. bras. zootec.

evaluation of feader and hair meals in combination with urea for ruminants. J. Anim. Sci., 53:345.

HELMER, L.G. 1970. Feed processing V - Effect of an expansionprocessed mixture of grain and urea (Starea) on nitrogen utilization in vidro. J. Dairy Sci., 53:330.

MATARAZO, S.V. 1996. Digestibilidade aparente da energia e da fibra bruta em rações para ovinos contendo uréia, amiréia ou farelo de algodão como fonte protéica exclusiva. Jaboticabal, $33 \mathrm{p}$.

MAYNARD, L.A., LOOSLI, J.K, HINTE, H.F. et al. 1979. Animal nutrition, 7.ed. New York: McGraw - Hill, 602p.

NATIONAL RESEARCH COUNCIL - NRC. 1989. Nutrient requirements of dairy cattle. Washington: National Academy of Science, $157 \mathrm{p}$.

NATIONAL RESEARCH COUNCIL - NRC. 1996. Nutrient requirement of dairy cattle. Washington: National Academy of Science, $242 \mathrm{p}$.

ORSKOV, E.R. 1982. Protein nutrition in ruminants. London: Academic Press, 641p.

OWENS, F.N. , BERGEN, W.G. 1983. Nitrogen metabolism of ruminant animals: Historical perspective, current understanding, and future implications. J. Anim. Sci. 57:498.

OWENS,F.N., ZINN, R. 1988. Metabolismo de la proteina en los ruminants. In: CHURCH, C.D. El ruminante: fisiología digestiva y nutrición. Zaragoza: Acribia, 641p.

OWENS, F.N., LUSBY, K.S., MIZWICKI, K. et al. 1980. Slow ammonia release from urea: rumen and metabolism studies. $J$. Anim. Sci., 50(3)527-31.

PARRÉ, C. Utilização da uréia e da zeolita na alimentação de ovinos. Jaboticabal, 1995, 96p. Tese (Doutorado em Zootecnia) - Faculdade de Ciências Agrárias e Veterinárias, Universidade Estadual Paulista.

REYNOLDS, C.K. 1992. Metabolism of nitrogenous compounds by ruminants liver. J. Nutr., 122(6):1251-5.

RUSSELL, J.B. Minimização das perdas de nitrogênio pelos ruminantes. In: SIMPÓSIO INTERNACIONAL EM RUMINANTES, 1992, Lavras. Anais ... p. 232-51.

SALMAN, A.K.D., MATARAZZO, S.V., EZEQUIEL, J.M.B. et al. 1997. Estudo do balanço nitrogenado e da digestibilidade da matéria seca e proteína de rações para ovinos, suplementadas com amiréia, uréia ou farelo de algodão. $R$. Bras. Zootec., 26(1):170-185.

SAMPAIO, A.A.M. Estudo da liberação de nitrogênio amoniacal in vitro e da ingestão total e parcial de nutrientes em bovinos alimentados com rações contendo farelo de algodão, levedura e uréia. Jaboticabal, 1989, 112p. Tese (Doutorado em Zootecnia) - Faculdade de Ciências Agrárias e Veterinárias, Universidade Estadual Paulista.

SILVA, D.J. 1981. Análise de alimentos (métodos químicos e biológico). 1.ed. Viçosa: UFV, Imp. Univ. 116p.

SILVA, J.F.C., PEREIRA, J.C., VALADARES FILHO, S.C. et al. 1994. Valor nutritivo da palha de arroz suplementada com amiréia, fubá + uréia e farelo de soja. Pesq. Agropec. Bras., 29(9):1475-81.

STEEL, R.G.D., TORRIE, J.H. 1960. Principles and procedures of statistics. New York: McGraw Hill, 481p.

STILES, D.A., BARTLEY, F.E., MEYER, R.M. et al. 1970. Feed processing. VII-Effect of an expansion-processed mixture of grain and urea (Starea) on nitrogen utilization in cattle and urea toxicity. J. Dairy Sci., 53:1436.

SWINGLE, R.S., ARAIZA, A. URIAS, A.R. 1977. Nitrogen utilization by lambs fed wheat straw alone or with supplements containing dried poutry waste, cottonseed meal or urea. J. Anim. Sci., 45(6):1435-41, 1977. In: Herbage Abstr. Farnham Royal, 48(9):364, (Abstract 3171).
Recebido em: 12/09/97

Aceito em: 22/09/98 